\title{
Inspeção ambiental baseada na nr-I 2: desenvolvimento de ferramenta e aplicação na área industrial
}

\author{
Environmental inspection based nr- /2: development of tools and application in industrial area \\ Luana Naiara Ferreira'; Maria Izabel da Silva Guerra'; Priscila Borges de Morais'; \\ Raphaella Marques Vilela'; Carlos Enrique de M. Jerônimo² \\ 'Aluno do Curso de Especialização em Engenharia de Segurança do Trabalho (UnP) \\ ${ }^{2}$ Professor da Universidade Potiguar (UnP)
}

\begin{abstract}
Resumo
O conhecimento dos elementos que envolvem o ambiente de trabalho é apontado como uma das formas preventivas de se eliminar riscos de problemas ambientais e exposição de agentes de forma desnecessária aos colaboradores do meio industrial. Diante desse quadro, inúmeras práticas para suporte a gestão da saúde e segurança ocupacional são desenvolvidas e aferidas pelo meio cientifico. O presente trabalho consiste no desenvolvimento de uma lista de verificação para avaliação das conformidades do ambiente industrial quanto aos elementos preconizados pela norma regulamentadora de número 12 do Ministério do Trabalho e Emprego. O trabalho foi desenvolvido por meio de pesquisas na literatura especializada e com a aferição do modelo desenvolvido em uma empresa prestadora de serviços na área industrial da cidade de Mossoró-RN, em especial para a indústria do Petróleo e Gás. Os resultados obtidos atestam à boa prática do emprego da metodologia sugerida e a possibilidade de um melhor acompanhamento das práticas necessárias a conformidade legal e a adoção de mecanismos de controle ambiental eficiente.
\end{abstract}

Palavras Chave: Indústria de Montagem. Condições Ambientais. Avaliação.

\begin{abstract}
Knowledge of elements that involve the work environment are identified as one of the preventive ways to eliminate risks of environmental problems and exposure to agents unnecessarily to employees of the industrial environment. Given this situation, many practices to support the management of occupational health and safety are developed and verified by scientific means. The present work is the development of a checklist for assessment of compliance of the industrial environment as the elements recommended by the regulatory norm of number 12 of the Ministry of Labour and Employment. The work was developed through research in the literature and the measurement model developed in a company providing services in the industrial area of the town of Mossoró, RN, especially for the Oil and Gas industry The results attest to the good practical employment of the suggested methodology and the possibility of better monitoring practices necessary legal compliance and the adoption of environmental control mechanisms efficiently.
\end{abstract}

Keywords: Assembly of Industry. Environmental Conditions. Evaluation 


\section{INTRODUÇÃO}

A partir da II Guerra Mundial, a mudança da base do carvão para o petróleo como matriz energética associada ao rápido avanço na tecnologia de sínteses químicas e de processos industriais, possibilitou o aumento no número e na capacidade de produção das refinarias de petróleo, que oferecem inúmeros e graves riscos em todas as suas atividades (Souza; Freitas, 2001).

O trabalho dos petroleiros ou prestadores de serviço da área tem como características principais ser uma atividade complexa, contínua, coletiva e perigosa. Envolve não só os acidentes triviais, mas também os acidentes ampliados que, incluindo materiais tóxicos, explosivos e inflamáveis, tem resultado em múltiplas conseqüências aos trabalhadores, às comunidades vizinhas, às indústrias e ao meio ambiente. Sobretudo, envolvendo a utilização de equipamentos e máquinas de elevado risco associado a sua operação (Alencar, 2009; Ayres, 2001).

A Norma Regulamentadora 12 (NR-12), cujo título é Segurança no Trabalho em Máquinas e Equipamentos, estabelece as medidas de prevenção da segurança e higiene do trabalho que devem ser adotadas pelas empresas no que diz respeito à instalação, operação e manutenção das máquinas e equipamentos, com o objetivo principal de prevenir possíveis acidentes de trabalho (Aguiar, 2011).

A NR-12 foi criada pela Portaria 3214, de 08 de junho de 1978, contudo já sofreu algumas alterações, sendo a última delas em 2010. É válido ressaltar que os artigos 184 e 186 da Consolidação das Leis do Trabalho (CLT) são os responsáveis pela fundamentação legal, ordinária e específica que dá fundamento jurídico à existência dessa Norma Regulamentadora (NR-12, 2010). Desta forma, o empregador deve atender os requisitos mínimos de cumprimento estabelecidos pela NR-12, uma vez que se trata de uma lei. Por isso, torna-se essencial a adoção de uma política de segurança eficaz pelo empregador, nos quais sejam dada ênfase aos parâmetros das normas aliado a outras técnicas e procedimentos cabíveis para os trabalhadores (Saliba, 2011).

As medidas de proteção adotadas pelo empregador devem abranger todos os funcionários da empresa, inclusive aqueles que são portadores de necessidade especial, de modo que a saúde e a integridade física, mental e intelectual dos trabalhadores sejam garantidas. Contudo, para que tais garantias sejam atendidas, os empregadores devem trabalhar em cima de uma ordem de prioridade, na qual a inserção do Equipamento de Proteção
Coletiva no local de trabalho está na primeira posição, com o objetivo de não sobrecarregar os empregados (Amorim, 2012). Entretanto, caso essa primeira condição não resolva o problema existente, a segunda medida que deve ser adotada são as condições administrativas, como mudança de layout do local de trabalho ou mudança de função do funcionário, conforme listam as normas do MTE: NR-06, 12 e 31. No entanto, se o problema persistir, a terceira medida a ser tomada é a adoção do uso de Equipamento de Proteção Individual (EPI), conforme MTE (2001).

Dentro desse contexto, o presente trabalho tem o objetivo de elaborar uma lista de verificação (check-list) para averiguar quais os requisitos da NR-12, tendo sido testada em uma empresa de Serviços Industriais quanto a sua conformidade ou não conformidade e, em seguida, apontando-se possíveis soluções para as não conformidades encontradas.

\section{MATERIAIS E MÉTODOS}

\section{I. Método}

$\mathrm{O}$ estudo constitui-se de uma pesquisa aplicada, pois objetiva levar conhecimentos para extensão do uso das principais técnicas e recomendações acerca da legislação dos programas de gerenciamento de riscos ambientais e na tratativa de casos fortuitos para os serviços de construção e montagem para instalações industriais.

Do ponto de vista dos objetivos, trata-se de um estudo exploratório-descritivo, o qual visa descrever a problemática em discussão, buscando caracterizar o objeto de estudo. Bem como, fazendo um estudo comparativo às pesquisas desenvolvidas para o monitoramento, gerenciamento e proposição de medidas mitigadoras dos riscos ambientais associados à atividade.

A hipótese pauta-se na possibilidade de haver alterações significativas e riscos a saúde humana nos casos analisados, em especial, pela exposição excessiva a não conformidades da NR-12 num ambiente de trabalho. Em outras palavras, espera-se que essa análise demonstre elementos para apoiar no aumento dos níveis de eficácia dos sistemas de gestão de segurança e saúde ocupacional.

Do ponto de vista dos procedimentos técnicos, o estudo caracteriza-se como pesquisa bibliográfica, por sua elaboração partir do levantamento e análise de material já publicado, como artigos científicos, livros, relatórios técnicos, etc. e (Silva; Menezes, 2001), e como estudo de caso devido à 
utilização de dados de campo.

A estrutura da pesquisa consiste em:

- Formulação do problema, englobando a justificativa do estudo, a determinação dos objetivos, a contextualização da problemática e definição da metodologia;

- Realização do levantamento teórico, que orienta a caracterização do objeto de estudo, as definições e conceitos a serem utilizados em análise e correntes de pensamentos que norteiam a hipótese da pesquisa;

- Levantamento de dados em campo, por meio de incursões investigativas em uma empresa que atua com atividades de montagem industrial, mais especificamente do estado do Rio Grande do Norte. Isso foi feito para aferição da metodologia;

- Estudo criterioso sobre o cumprimento dos requisitos atribuídos pela Norma Regulamentadora do Ministério do Trabalho e Emprego (MTE) de número 12;

- Realização de uma análise estatística dos dados obtidos e desdobramento numa análise preliminar de riscos.

Os dados coletados em campos foram organizados, de acordo com a necessidade da utilização em pesquisa, e utilizados para elaboração do levantamento das principais ações de oportunidades (Camacho, 2004).

\subsection{Espaço Amostral}

A empresa utilizada como piloto está instalada em um espaço de aproximadamente 400 metros quadrados, localizada em Mossoró, no Rio Grande do Norte. A empresa se enquadrada como uma microempresa e possui 17 funcionários trabalhando, sendo um Engenheiro Mecânico, de Segurança do Trabalho e de Petróleo o proprietário da empresa.

A empresa atua em serviços industriais que concilia técnica e perícia profissional com equipamentos de última geração. A empresa atua no segmento de manutenção de equipamentos relacionado ao ramo da produção de petróleo, mas atendendo também as indústrias salineiras, entre outras. Dentre os serviços prestados, tem-se a soldagem; tornearia; recuperação e manutenção de válvulas, bombas de lama, e outros equipamentos petrolíferos e salineiros em geral, atendendo assim as principais empresas do setor nessa região.

A gestão da organização está divida nos seguintes setores: o setor de tornearia que conta com três tornos universais, cada um com um operador; o setor de furadeiras, onde há uma furadeira radial, que é utilizada em perfurações de peças pesadas; o setor de pintura; o setor de válvulas e de bombas; o setor de solda e o almoxarifado, cada um com seus respectivos responsáveis.

\subsection{Lista de Verificação}

Como ferramenta para nortear e facilitar o gerenciamento da norma regulamentadora na observação dos aspectos relativos ao ambiente de trabalho foi desenvolvida uma lista de verificação, conforme segue no Quadro 1.

\section{RESULTADOS E DISCUSSÃO}

Quadro 1. Lista de Verificação Idealizada para a Inspeção de Conformidade da NR-12

\begin{tabular}{|c|c|c|c|}
\hline $\begin{array}{l}\text { ITEM DA NORMA } \\
\text { ABRANGIDO }\end{array}$ & DESCRIÇÃO & SIM & NÃO \\
\hline 12.38 & $\begin{array}{l}\text { O empregador adota medidas de proteção para o trabalho em máquinas e equipamentos, capazes } \\
\text { de garantir a saúde e a integridade física dos trabalhadores sem comprometer as características } \\
\text { técnicas das máquinas e dos processos de trabalho? }\end{array}$ & & \\
\hline 12.6 & $\begin{array}{l}\text { As áreas de circulação próximas às máquinas e equipamentos são devidamente demarcadas } \\
\text { conforme as normas técnicas oficiais? }\end{array}$ & & \\
\hline 12.6 .1 & $\begin{array}{l}\text { As vias principais de circulação têm, no mínimo, } 1,20 \mathrm{~m} \text { de largura e são mantidas } \\
\text { permanentemente desobstruídas? }\end{array}$ & & \\
\hline 12.0 & $\begin{array}{l}\text { Os espaços ao redor das máquinas e equipamentos são adequados ao seu tipo e ao tipo de } \\
\text { operacão (de forma a prevenir a ocorrência de acidentes e doencas relacionados ao trabalho)? }\end{array}$ & & \\
\hline 12.8.1 & $\begin{array}{l}\text { A distancia minima entre maquinas garantem a segurança dos trabalhadores durante sua } \\
\text { operação, manutenção, ajuste, limpeza e inspeção, e permitem a movimentação adequada para } \\
\text { execucão da tarefa? }\end{array}$ & & \\
\hline 12.8 .2 & $\begin{array}{l}\text { As areas de circulação e armazenamento de materiais e os espaços em torno de máquinas } \\
\text { permitem que os trabalhadores e os transportadores de materiais movimentem-se com seguranca? }\end{array}$ & & \\
\hline 12.9 & $\begin{array}{l}\text { Os pisos dos locais de trabaho sẫo limpos, nivelados, resistentes as cargas as quais estâo sujettas, } \\
\text { não escorregadios e desobstruídos? }\end{array}$ & & \\
\hline 12.10 & $\begin{array}{l}\text { As ferramentas utilizadas são organizadas e armazenadas ou dispostas em locais específicos para } \\
\text { essa finalidade? }\end{array}$ & & \\
\hline
\end{tabular}


Quadro 1. continuação...

\begin{tabular}{|c|c|c|c|}
\hline $\begin{array}{l}\text { ITEM DA NORMA } \\
\text { ABRANGIDO }\end{array}$ & DESCRIÇÃO & SIM & NÃO \\
\hline 12.11.1 & $\begin{array}{l}\text { As máquinas estacionárias possuem medidas preventivas quanto à sua estabilidade e respeitam } \\
\text { os requisitos necessários fornecidos pelos fabricantes ou elaborados por um profissional } \\
\text { legalmente habilitado? }\end{array}$ & & \\
\hline 12.14 & As instalações elétricas das máquinas e equipamentos estão conforme previsto na NR $10 ?$ & & \\
\hline $12.17(\mathrm{a}, \mathrm{b}, \mathrm{c}, \mathrm{d}, \mathrm{e}, \mathrm{f})$ & & & \\
\hline 12.20 & $\begin{array}{l}\text { Os condutores de alimentação elétrica das máquinas e equipamentos estão dimensionados } \\
\text { corretamente, possuem proteção, são auto-extinguíveis e embutidos ou fixado na parede? }\end{array}$ & & \\
\hline $12.21(c)$ & & & \\
\hline $12.18(a, c)$ & $\begin{array}{l}\text { Os quadros de energia das máquinas e equipamentos possuem porta de acesso, mantida } \\
\text { permanentemente fechada, e são mantidos em bom estado de conservação, limpos e livres de } \\
\text { objetos e ferramentas? }\end{array}$ & & \\
\hline $12,18(b, d)$ & $\begin{array}{l}\text { Os quadros de energia das máquinas e equipamentos possuem proteção, identificação dos } \\
\text { circuitos e sinalização quanto ao perigo de choque elétrico e restrição de acesso por pessoas } \\
\text { não autorizadas? }\end{array}$ & & \\
\hline 12.19 & $\begin{array}{l}\text { As ligaçôes e derivações dos condutores elétricos das máquinas e equipamentos são feitas } \\
\text { mediante disnositivos anropriados e conforme as normas técnicas oficiais vioentes? }\end{array}$ & & \\
\hline 12.21 (b) & As máquinas e equipamentos não utilizam a chave geral como dispositivo de partida e parada? & & \\
\hline 12.22 & A empresa possui baterias? & & \\
\hline $12.24(\mathrm{a}, \mathrm{b}, \mathrm{c}, \mathrm{d}, \mathrm{e})$ & $\begin{array}{l}\text { Os dispositivos de partida, acionamento e parada das máquinas não estão localizados em zonas } \\
\text { perigosas, nem podem ser burlados; podendo ser acionada ou desligada apenas em caso de } \\
\text { emergência. seia pelo operador ou por outra pessoa. }\end{array}$ & & \\
\hline 12.25 & $\begin{array}{l}\text { Os comandos de partidá ou acionamento das maquinas possuem dispositivos que impeçam seu } \\
\text { funcionamento automático ao serem energizados? }\end{array}$ & & \\
\hline 12.26 & São utilizados dispositivos de acionamento do tipo comando bimanual? & & \\
\hline 12.30 & Há máquinas e equipamentos cuja operação requeira a participação de mais de uma pessoa? & & \\
\hline 12.31 & $\begin{array}{l}\text { Há máquinas ou equipamentos que permite a utilizaçáo de varios modos de comando ou de } \\
\text { funcionamento que apresentem níveis de seguranca diferentes? }\end{array}$ & & \\
\hline 12.32 & $\begin{array}{l}\text { As máquinas e equipamentos, cujo acionamento por pessoas não autorizadas possam oferecer } \\
\text { risco à saúde ou integridade física de qualquer pessoa, possuem sistema que possibilite o } \\
\text { bloqueio de seus dispositivos de acionamento? }\end{array}$ & & \\
\hline 12.36 & $\begin{array}{l}\text { Ha componentes de partida, parada, acionamento e outros controles que compõem a interface } \\
\text { de operação das máquinas? }\end{array}$ & & \\
\hline $12.39(\mathrm{a}, \mathrm{b}, \mathrm{c}, \mathrm{d})$ & $\begin{array}{l}\text { Os sistemas de segurança são selecionados e instalados sob a responsabilidade técnica de } \\
\text { profissional legalmente habilitado, de modo que não possam ser neutralizados ou burlados } \\
\text { e atendam as categorias de segurança conforme prévia análise de riscos prevista nas normas } \\
\text { técnicas oficiais vigentes? }\end{array}$ & & \\
\hline 12.39 (f) & $\begin{array}{l}\text { Os sistemas de segurança paralisam os movimentos perigosos e demais riscos quando ocorrerem } \\
\text { falhas ou situacões anormais de trabalho? }\end{array}$ & & \\
\hline 12.40 & $\begin{array}{l}\text { Os sistemas de segurançaexigem rearme, ou reset manual, somente após a correção da falha ou } \\
\text { situação anormal de trabalho que provocou a paralisação da máquina? }\end{array}$ & & \\
\hline $12.49(a, b, c, d)$ & $\begin{array}{l}\text { As máquinas e equipamentos que ofereçam risco de ruptura de suas partes, projeção de materiais, } \\
\text { partículas ou substâncias, possuem proteções projetadas e construídas que garantam a saúde, a } \\
\text { seguranca dos trabalhadores e atende aos requisitos de seguranca das normas vigentes? }\end{array}$ & & \\
\hline 12.54 & $\begin{array}{l}\text { Segurança dos trabainadores e atende aos requisitos de segurança das normas vigentes? } \\
\text { Os dispositivos de segurança integram as máquinas e equipamentos? }\end{array}$ & & \\
\hline 12.55 .1 & $\begin{array}{l}\text { Há documentação técnica dos sistemas de segurança das máquinas, conforme as normas vigentes } \\
\text { ou elaborado por um profissional legalmente habilitado e com ART/CREA? }\end{array}$ & & \\
\hline 12.56 .1 & $\begin{array}{l}\text { As máquinas são equipadas com um ou mais dispositivos de parada de emergência, no qual os } \\
\text { mesmos não são utilizados como dispositivos de partida ou de acionamento e estão posicionados } \\
\text { em locais de fácil acesso e visualização, e mantidos permanentemente desobstruídos? }\end{array}$ & & \\
\hline $\begin{array}{l}12.58(a, b, c, d, \\
\quad \mathrm{e}, \mathrm{g})\end{array}$ & $\begin{array}{l}\text { Os dispositivos de parada de emergência são usados como medida auxiliar, sendo selecionados, } \\
\text { montados e interconectados de forma que sua atuação seja fácil e suporte as condições de } \\
\text { operação previstas, sendo mantido em perfeito estado de funcionamento; prevalecendo sobre } \\
\text { todos os outros comandos e realizando a parada sem provocar riscos? }\end{array}$ & & \\
\hline $12.58(\mathrm{f})$ & Os dispositivos de parada de emergência são monitorados por meio de sistemas de segurança? & & \\
\hline $12.59(a, b, c)$ & $\begin{array}{l}\text { A função parada de emergência não prejudica a eficiência do sistema de segurança ou gera riscos } \\
\text { adicionais? }\end{array}$ & & \\
\hline 12.60 & $\begin{array}{l}\text { O acionamento do dispositivo de parada de emergência é manual e resulta na retenção do } \\
\text { acionador? }\end{array}$ & & \\
\hline 12.64.3 & $\begin{array}{l}\text { As máquinas e equipamentos possuem acessos permanentemente fixados e seguros a todos os } \\
\text { seus pontos, de modo a prevenir riscos de acidente e facilitar o seu acesso e utilização pelos } \\
\text { trabalhadores? }\end{array}$ & & \\
\hline $12.68(a, b, c, d)$ & $\begin{array}{l}\text { As rampas propiciam condições seguras de trabalho, são mantidas desobstruídas; e construídas } \\
\text { de tal modo que previna acidentes e dispêndio excessivo de esforços? }\end{array}$ & & \\
\hline 12.73 (a) & As rampas possuem largura útil mínima de $0,60 \mathrm{~m}$ (sessenta centímetros)? & & \\
\hline
\end{tabular}


Quadro 1. continuação...

\begin{tabular}{|c|c|c|c|}
\hline $\begin{array}{l}\text { ITEM DA NORMA } \\
\text { ABRANGIDO }\end{array}$ & DESCRIÇÃO & SIM & NÃO \\
\hline $\begin{array}{l}12.74 \\
12.75\end{array}$ & Existem escadas de degraus com ou sem espelho? & & \\
\hline 12.76 & Existem escadas fixas do tipo marinheiro? & & \\
\hline 12.78 & $\begin{array}{l}\text { As mangueiras, tubulações e demais componentes pressurizados são localizados ou protegidos de } \\
\text { tal forma que em uma situação de eventuais impactos mecânicos (ou outros agentes agressivos); } \\
\text { ruptura desses componentes;ou vazamentos de fluidos, não possam ocasionar acidentes de } \\
\text { trabalho? }\end{array}$ & & \\
\hline 12.79 & $\begin{array}{l}\text { trabalho? } \\
\text { As mangueiras utilizadas nos sistemas pressurizados possuem indicação da pressão máxima de } \\
\text { trabalho admissível especificada pelo fabricante? }\end{array}$ & & \\
\hline $12.80(a, b)$ & $\begin{array}{l}\text { Os sistemas pressurizados das maquinas possuem meios que garantem que a pressão máxima de } \\
\text { trabalho admissível não possa ser excedida; as quedas de pressão; e perdas de vácuo não possam } \\
\text { gerar nerigo? }\end{array}$ & & \\
\hline 12.82 & $\begin{array}{l}\text { Os recipientes contendo gases comprimidos utilizados em máquinas e equipamentos permanecem } \\
\text { em perfeito estado de conservação e funcionamento e são armazenados em depósitos bem }\end{array}$ & & \\
\hline $\begin{array}{l}12.87 \\
12.88\end{array}$ & $\begin{array}{l}\text { Ventuados, protegldos contra quedas, calor e lmpactos acientents? } \\
\text { Os transportadores de materials são utilizados somente para o tipo e capacidade de carga para os } \\
\text { quais foram projetados, sendo todos os seus elementos e conexões adequados ao tipo de material } \\
\text { e dimensionados para suportar os esforcos solicitantes? }\end{array}$ & & \\
\hline 12.93 & $\begin{array}{l}\text { Durante o transporte de materiais suspensos são adotadas medidas de segurança visando a } \\
\text { garantir que não haja pessoas sob a carga? }\end{array}$ & & \\
\hline $12.94(\mathrm{a}, \mathrm{b}, \mathrm{g})$ & & & \\
\hline $\begin{array}{l}12.101(\mathrm{a}, \mathrm{b}, \mathrm{c}) \\
12.102\end{array}$ & $\begin{array}{l}\text { As máquinas e equipamentos, bem como os postos de trabalho são projetados, construídos e } \\
\text { mantidos com observância respeitando a variabilidade das características antropométricas dos } \\
\text { operadores e às exigências posturais, e esforços físicos demandados pelos operadores, de modo } \\
\text { que reduz a exigência de força ou torção? }\end{array}$ & & \\
\hline 12.103 & & & \\
\hline $12.94(d, e)$ & $\begin{array}{l}\text { Os comandos e indicadores das máquinas e equipamentos representam a direção do movimento } \\
\text { e demais efeitos e os sistemas interativos são coerentes em sua aparência e função? }\end{array}$ & & \\
\hline $12.94(f, h)$ & $\begin{array}{l}\text { As máquinas e equipamentos favorecem o desempenho e a confiabilidade das operações e } \\
\text { possuem a iluminação adequada? }\end{array}$ & & \\
\hline $12.95(a, b, c, d, e)$ & $\begin{array}{l}\text { Os comandos das máquinas e equipamentos são projetados, construídos e mantidos com } \\
\text { visibilidade, identificação e sinalização que permita serem distinguíveis entre si, além disso, } \\
\text { permitindo o manejo fácil, rápido e seguro, sendo os comandos mais utilizados estando em } \\
\text { posições mais acessíveis ao operador e os elementos de acionamento manual (ou a pedal) } \\
\text { instalados de forma a facilitar a execução da manobra? }\end{array}$ & & \\
\hline 12.96 & $\begin{array}{l}\text { As Máquinas e equipamentos são projetados, construídos e operados levando em consideração } \\
\text { o disposto na NR } 17 \text { ? }\end{array}$ & & \\
\hline 12.98 & $\begin{array}{l}\text { Os postos de trabalho são projetados para permitir a alternância de postura e a movimentação } \\
\text { adequada dos segmentos corporais e permitem o apoio integral das plantas dos pés de piso? }\end{array}$ & & \\
\hline 12.99 & $\begin{array}{l}\text { As superfícies dos postos de trabalho não possuem rebarbas nos pontos de contato com segmentos } \\
\text { do corpo do operador, e os elementos de fixação são mantidos de forma a não acrescentar riscos } \\
\text { à operação? }\end{array}$ & & \\
\hline 12.103.1 & $\begin{array}{l}\text { A iluminação das partes internas das máquinas e equipamentos que venham a requerer operações } \\
\text { são adequadas e estão disponíveis em situações de emergência? }\end{array}$ & & \\
\hline 12.104 & $\begin{array}{l}\text { O ritmo de trabalho e a velocidade das máquinas e equipamentos são compatíveis com a } \\
\text { capacidade física dos operadores. de modo a evitar agravos à saúde? }\end{array}$ & & \\
\hline 12.109 & $\begin{array}{l}\text { São adotadas medidas de proteção contra queimaduras causadas pelo contato da pele com } \\
\text { superfícies aquecidas de máquinas e equipamentos? }\end{array}$ & & \\
\hline 12.111 & $\begin{array}{l}\text { As máquinas e equipamentos são submetidos à manutenção preventiva e corretiva, na forma e } \\
\text { periodicidade determinada pelo fabricante? }\end{array}$ & & \\
\hline 12.111.1 & $\begin{array}{l}\text { As manutenções preventivas com potencial de causar acidentes do trabalho são objeto de } \\
\text { planejamento e gerenciamento efetuado por profissional legalmente habilitado? }\end{array}$ & & \\
\hline $\begin{array}{l}12.112(\mathrm{a}, \mathrm{b}, \mathrm{c}, \mathrm{d}, \mathrm{e}, \\
\mathrm{f}, \mathrm{g}, \mathrm{h})\end{array}$ & $\begin{array}{l}\text { As manutenções preventivas e corretivas são registradas em livro próprio, ficha ou sistema } \\
\text { informatizado? }\end{array}$ & & \\
\hline 12.113 & $\begin{array}{l}\text { A manutenção com intervenções são executadas por profissionais autorizados pelo empregador, } \\
\text { com as máquinas e equipamentos parados? }\end{array}$ & & \\
\hline $12.113(\mathrm{a}, \mathrm{c})$ & $\begin{array}{l}\text { Durante as intervençoes são adotados isolamento e descarga de todas as fontes de energia das } \\
\text { máquinas e equipamentos; e medidas que garantem, à jusante dos pontos de corte de energia, a } \\
\text { impossibilidade de gerar risco de acidentes? }\end{array}$ & & \\
\hline $12.113(\mathrm{~b}, \mathrm{e})$ & $\begin{array}{l}\text { Durante as intervençôes são adotados bloqueio mecânico e elétrico na posição "desligado" ou } \\
\text { "fechado" de todos os dispositivos de corte de fontes de energia e sistemas de retenção com trava } \\
\text { mecânica, para evitar o movimento de retorno acidental de partes basculadas ou articuladas } \\
\text { abertas das máquinas e equinamentos? }\end{array}$ & & \\
\hline 12.114.1 & $\begin{array}{l}\text { Os ensaios não destrutivos - END, quando realizados, atendem às normas técnicas oficiais } \\
\text { vigentes? }\end{array}$ & & \\
\hline
\end{tabular}

continua... 


\begin{tabular}{|c|c|c|c|}
\hline $\begin{array}{l}\text { ITEM DA NORMA } \\
\text { ABRANGIDO }\end{array}$ & DESCRIÇÃO & SIM & NÃO \\
\hline 12.115 & $\begin{array}{l}\text { Nas manutenções das máquinas e equipamentos, sempre que detectado qualquer defeito, sua } \\
\text { reparação ou substituição é imediata, de modo que garanta as mesmas características e condições } \\
\text { seguras de uso? }\end{array}$ & & \\
\hline $\begin{array}{r}12.116 \\
12.116 .3\end{array}$ & $\begin{array}{l}\text { As máquinas e equipamentos, bem como as instalações em que se encontram, possuem } \\
\text { sinalização de segurança para advertir os trabalhadores e terceiros sobre os riscos a que estão } \\
\text { expostos? }\end{array}$ & & \\
\hline $12.117(a, b)$ & $\begin{array}{l}\text { A sinalização de segurança fica destacada na máquina ou equipamento e em local claramente } \\
\text { visível? }\end{array}$ & & \\
\hline 12.117 (c) & A sinalização de segurança é de fácil compreensão? & & \\
\hline 12.118 & $\begin{array}{l}\text { Os símbolos, inscrições e sinais luminosos e sonoros seguem os padrões estabelecidos pelas } \\
\text { normas técnicas vigentes? }\end{array}$ & & \\
\hline $\begin{array}{l}12.119(a, b) \\
12.127(a, b)\end{array}$ & $\begin{array}{l}\text { As inscrições das máquinas e equipamentos e os seus respectivos manuais são legíveis e escritas } \\
\text { em português? }\end{array}$ & & \\
\hline $12.127(\mathrm{c})$ & $\begin{array}{l}\text { As inscrições das máquinas e equipamentos e os seus respectivos manuais indicam claramente } \\
\text { o risco? }\end{array}$ & & \\
\hline 12.120 & $\begin{array}{l}\text { As inscrições e símbolos são utilizados nas máquinas e equipamentos para indicar as suas } \\
\text { especificações e limitações técnicas? }\end{array}$ & & \\
\hline $12.122(a, b)$ & $\begin{array}{l}\text { São adotadas cores para a sinalização de segurança das máquinas e equipamentos a cor amarela } \\
\text { para proteções fixas e móveis, componentes mecânicos de retenção, dispositivos e outras partes } \\
\text { destinadas à segurança, gaiolas das escadas, corrimãos e sistemas de guarda-corpo e rodapé; e } \\
\text { azul para comunicacão de paralisacão e bloqueio de segurança para manutenção? }\end{array}$ & & \\
\hline $\begin{array}{l}12.123(\mathrm{a}, \mathrm{b}, \mathrm{c}, \mathrm{d}, \mathrm{e}) \\
12.128(\mathrm{a}, \mathrm{b}, \mathrm{c})\end{array}$ & $\begin{array}{l}\text { As maquinas e equipamentos fabricados a partir da vigência desta Norma, bem como seus } \\
\text { respectivos manuais possuem razão social, CNPJ e endereço do fabricante ou importador; } \\
\text { informações sobre tipo, modelo e capacidade; número de série ou identificação, e ano de } \\
\text { fabricação; número de registro do fabricante ou importador no CREA; e peso da máquina ou } \\
\text { equipamento? }\end{array}$ & & \\
\hline 12.124.1 & $\begin{array}{l}\text { Para advertir os trabalhadores sobre os possíveis perigos, são instalados dispositivos indicadores } \\
\text { de leitura de controle de segurança de fácil leitura e distinguíveis uns dos outros? }\end{array}$ & & \\
\hline 12.127 (d) & Os manuais permanecem disponíveis a todos os usuários nos locais de trabalho? & & \\
\hline $\begin{array}{l}12.128(\mathrm{~d}, \mathrm{e}, \mathrm{f}, \mathrm{g} \\
\mathrm{h}, \mathrm{i})\end{array}$ & $\begin{array}{l}\text { Os manuais das máquinas e equipamentos importados a partir da vigência desta Norma contêm } \\
\text { as normas observadas para o projeto e construção da máquina ou equipamento, com sua descrição } \\
\text { detalhada, seus diagramas, a definição da utilização prevista, bem como os riscos a que os } \\
\text { usuários estão expostos e as medidas de segurança existentes ou que devem ser adotadas? }\end{array}$ & & \\
\hline $\begin{array}{l}12.128(\mathbf{j}, \mathbf{k}, \mathbf{l}, \mathbf{m}, \mathbf{n}, \\
\quad \mathbf{0}, \mathbf{p})\end{array}$ & $\begin{array}{l}\text { Os manuais das máquinas e equipamentos importados a partir da vigência desta Norma contêm } \\
\text { as especificações, procedimentos e limitações técnicas para a sua utilização com segurança; a } \\
\text { vida útil,; os procedimentos e periodicidade para inspeções e manutençôes; os procedimentos } \\
\text { adotados em situações de emergência, bem como os riscos que podem resultar se ocorrer } \\
\text { utilizações diferentes daquelas previstas? }\end{array}$ & & \\
\hline 12.131 & $\begin{array}{l}\text { O operador efetua inspeção rotineira das condições de operacionalidade e segurança da máquina } \\
\text { e, se constatadas anormalidades que afetem a segurança, as atividades são interrompidas, com a } \\
\text { comunicacão ao superior hierárquico? }\end{array}$ & & \\
\hline 12.135 & $\begin{array}{l}\text { A operação e as intervenções em máquinas e equipamentos são realizadas por trabalhadores } \\
\text { habilitados, qualificados, capacitados ou autorizados para este fim? }\end{array}$ & & \\
\hline 12.137 & $\begin{array}{l}\text { Os operadores de máquinas e equipamentos são maiores de dezoito anos, exceto na condição de } \\
\text { aprendiz? }\end{array}$ & & \\
\hline 12.145 & $\begin{array}{l}\text { A função do trabalhador que opera e realiza intervenções em máquinas é anotada no registro de } \\
\text { empregado e em sua Carteira de Trabalho e Previdência Social (CTPS)? }\end{array}$ & & \\
\hline 12.148 & $\begin{array}{l}\text { As ferramentas, acessórios materiais utilizados pelas máquinas e equipamentos, bem como nas } \\
\text { suas intervenções são adequados às operações realizadas? }\end{array}$ & & \\
\hline 12.153 & $\begin{array}{l}\text { O empregador mantém inventário atualizado das máquinas e equipamentos com identificação } \\
\text { por tipo, capacidade, sistemas de segurança e localização em planta baixa, elaborado por } \\
\text { profissional qualificado ou legalmente habilitado; de modo que auxiliam as ações de gestão para } \\
\text { aplicação da NR-12? }\end{array}$ & & \\
\hline
\end{tabular}

\section{I. Diagnóstico Ambiental}

Os resultados demonstram a validação da inspeção realizada na organização, aplicação feita após uma vistoria inicial no ambiente. Diante desse quadro foi possível observar que alguns dos itens da norma em estudo não são aplicáveis ao ambiente da empresa. Desta forma, serão apresentadas as principais conformidades que garantem a preven- ção da segurança e higiene do trabalho, bem como do trabalhador, que foram observadas na empresa. Bem como, os elementos em desconformidade e oportunidades de melhoria, provenientes da avaliação da metodologia proposta e baseado em recomendações de SESI-SEBRAE (2005).

$O$ principal requisito atendido pela empresa foi à adoção de medidas de proteção para o trabalho 


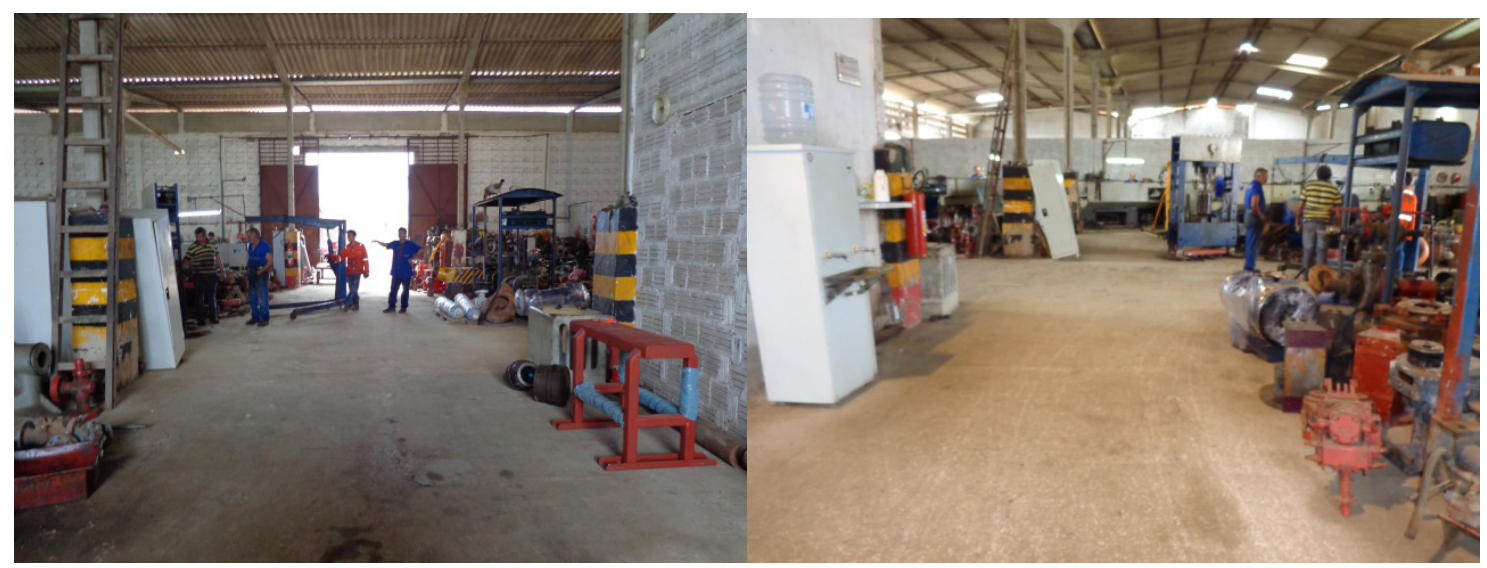

Figura 1 - Principais vias de circulação da empresa em estudo Fonte: Elaboração própria

em máquinas e equipamentos, capazes de garantir a saúde e a integridade física dos trabalhadores sem comprometer as características técnicas das máquinas e dos processos de trabalho, atendendo assim, os itens $12.3,12.38$ e 12.38 .1 da NR-12. Também foi perceptível, como é mostrado na Figura 1 , que as principais vias de circulação da empresa possuem a largura mínima de $1,20 \mathrm{~m}$, estabelecido no item 12.6.1, e são mantidas permanentemente desobstruídas, como exige o item 12.6.2. Além disso, os espaços ao redor das máquinas permitem a movimentação adequada no decorrer da execução da atividade e ainda garantem a segurança dos trabalhadores durante a operação, manutenção, ajuste, limpeza e inspeção dessas máquinas, como são determinados nos itens $12.8,12.8 .1 \mathrm{e}$ 12.8.2; e os pisos dos locais de trabalho são limpos, nivelados e resistentes, logo, permanecendo em conformidade com o item 12.9 da norma.

Quanto às ferramentas utilizadas na empresa, às mesmas são organizadas e armazenadas em locais específicos, o que contribui para a organização do almoxarifado da empresa e ainda atende ao requisito 12.10 da Norma. Com relação às máquinas estacionárias, elas são alocadas de modo que sua estabilidade seja garantida e os requisitos necessários estabelecidos pelo fornecedor sejam atendidos, o que consente os itens $12.11 \mathrm{e}$ 12.11.1 da NR-12.

No que diz respeito às instalações e dispositivos elétricos, as ligações e derivações das máquinas e equipamentos são realizadas com os dispositivos apropriados e de acordo com as normas vigentes, desta forma, atendendo ao item $12.19 \mathrm{da}$ norma estudada. Além disso, os condutores de alimentação elétrica utilizados pelas máquinas e equipamentos estão dimensionados corretamente, possuem proteção, são auto-extinguíveis e encontram-se embutidos ou fixados na parede, de maneira que atende aos itens 12.17 (a, b, c, d, e, f) e 12.21 (c). É importante frisar, que obedecendo ao item 12.21 (b), a chave geral da empresa não é utilizada como dispositivo de partida e parada.

Os dispositivos de partida, acionamento e parada não funcionam automaticamente ao serem energizados, possuem sistemas que bloqueiam o acionamento por pessoas não autorizadas, não estão localizados em zonas perigosas e nem podem ser burlados. Todo o sistema de segurança dos dispositivos existentes na empresa são selecionados e instalados sob a responsabilidade técnica de um profissional legalmente habilitado. Diante do exposto, os itens 12.24 (a, b, c, d, e), 12,25, 12,32 e 12.39 ( $a, b, c, d)$ da NR-12 também são atendidos.

Os sistemas de segurança em máquinas e equipamentos é um dos requisitos fundamentais que as empresas devem acatar. É nesse contexto, que a empresa adquiriu máquinas, cujo seus sistemas de segurança exigem o rearme ou reset manual somente após a correção da situação anormal que provocou a paralisação da máquina.

Ela também teve a preocupação de optar por máquinas e equipamentos que possuíssem dispositivos de segurança integrados a elas e proteções fixas e móveis que garantisse a saúde e a segurança dos trabalhadores.

Todos os sistemas de segurança existentes nas máquinas e equipamentos da empresa estão em conformidade com as normas vigentes. Tais sistemas permitiram que a empresa atendesse aos itens $12.40,12.48,12.49$ (a, b, c, d) , 12.54, 12.55, 12.55.1 e 12.63 .

Os dispositivos de parada de emergência é um dos componentes das máquinas e equipamentos utilizados na empresa. Esses dispositivos são usados como medida auxiliar e seu acionamento são realizados manualmente, de tal modo que não prejudica a eficiência do sistema de segurança e 
nem gera riscos. Tais características fazem com que a empresa obedeça aos itens 12.56, 12.56.1, 12.7, 12.58 (a, b, c, d, e, g), 12.59 (a, b, c), 12.60 e 12.60 .1

Para prevenir riscos de acidente e também facilitar a circulação dos trabalhadores, os acessos das máquinas e equipamentos são fixados e seguros, obedecendo assim aos requisitos 12.64 e 12.64.3.

Quanto à rampa existente na empresa, essa proporciona condições seguras de trabalho e, assim como as vias de circulação, permanece desobstruídas, o que atende as condições estabelecidas nos itens 12.68 (a, b,c, d). Além disso, como sua largura é superior a sessenta centímetros, ela obedece também ao item 12.73 (a).

Dentre os setores da empresa apresentados, um deles apresenta componentes pressurizados para realização de testes, que é o setor de válvulas e de bombas. Desta forma, a lista de verificação necessitou ser aplicada nesse setor de tal modo que os componentes pressurizados existentes fossem avaliados.

Nessa vistoria, foi perceptível que os componentes pressurizados do setor são protegidos de tal forma que em situações de eventuais impactos, acidentes de trabalho não sejam gerados. Observou-se também que a pressão máxima de trabalho admissível pelos sistemas pressurizados não podem ser ultrapassados. Outro ponto analisado foi a utilização de mangueiras adequadas para a pressão que será submetida. Portanto, é possível afirmar que os itens $12.77,12 ; 78,12.79,12.80$ (a, b) e 12.82 da NR-12 foram atendidos pela empresa.

Os transportadores de materiais da empresa são utilizados apenas para o tipo e capacidade de carga para os quais foram projetados. A equipe da empresa também se preocupa em adotar medidas de segurança durante o transporte de materiais suspensos para que não haja circulação de pessoas sob a carga. Ao adotar essas medidas, a empresa satisfaz as exigências determinadas nos itens 12.87 , 12.88 e 12.93.

Outro ponto abordado na NR-12 são os aspectos ergonômicos das máquinas e equipamentos, bem como dos postos de trabalho. Após a visita na empresa em estudo, observou-se que os itens $12.94(\mathrm{a}, \mathrm{b}, \mathrm{g}), 12.94(\mathrm{~d}, \mathrm{e}), 12.94(\mathrm{f}, \mathrm{h})$, 12.95 (a. b. c. d. e), $12.96,12.98,12.100,12.101$ $(\mathrm{a}, \mathrm{b}, \mathrm{c}), 12.102,12.103,12.103 .1$ e 12.104 .

De maneira geral, dentre os diversos aspectos positivos, foi possível observar que as máquinas e equipamentos favorecem o desempenho e a confiabilidade das operações e também possuem a iluminação adequada para o operador. Além disso, as máquinas e equipamentos utilizados pela empresa consideram o disposto na NR-12.

Em relação aos postos de trabalho, é possível destacar que o empregador preocupou-se em projetá-lo de tal modo, que fossem realizadas as movimentações adequadas pelo operador e ainda possibilitasse o apoio integral das plantas dos pés no piso, o que fica igualmente visível na Figura 10.

De acordo com o proprietário e os funcionários da empresa, as máquinas e equipamentos da empresa são submetidos à manutenção preventiva e corretiva periodicamente, e também a manutenções com intervenções, nas quais todas elas são planejadas e gerenciadas por um profissional legalmente habilitado; e também são isoladas das fontes de energia, conforme acordado nos itens $12.111,12.111 .1,12.113$ e 12.113 (a, c)

No caso da apresentação de um defeito nas máquinas e equipamentos, o engenheiro da empresa afirmou que a reparação ou substituição ocorre imediatamente, de acordo como exige o item 12.115 da Norma Regulamentadora. Ele também afirma que os ensaios não destrutivos realizados na empresa atendem às normas técnicas oficiais vigentes, bem como ao item 12.114.1 da NR-12.

Apesar de não apresentarem grande destaque dentro da empresa, a sinalização existente é de fácil compreensão; os símbolos seguem as normas vigentes; e as inscrições são responsáveis pela indicação das especificações e limitações técnicas das máquinas e equipamentos, atendendo assim, aos itens 12.117 (c), 12.118 e 12.120 .

É válido ressaltar que as inscrições das máquinas, equipamentos e seus respectivos manuais são escritos em português, possuem razão social, CNPJ, endereço do fabricante, informações sobre tipo, número de série, ano de fabricação, número de registro do fabricante e peso da máquina. Além disso, todos os manuais permanecem disponíveis a todos os usuários nos locais de trabalho.

O principal procedimento de trabalho e segurança realizado na empresa é a inspeção rotineira das condições de operacionalidade e segurança da máquina efetuado pelo operador que utiliza a devida máquina. Também fica sob a responsabilidade do trabalhador avisar ao empregador e interromper as atividades no caso de existir condições anormais que afetem a segurança, assim como é estabelecido no item 12.131 da NR-12.

De acordo com o proprietário da empresa na qual o estudo foi realizado, a operação e intervenções são executadas por funcionários maiores de dezoito anos; todos habilitados, qualificados, capacitados ou autorizados, e com suas funções anotadas no registro de empregado, bem como em sua Carteira de Trabalho e Previdência Social 


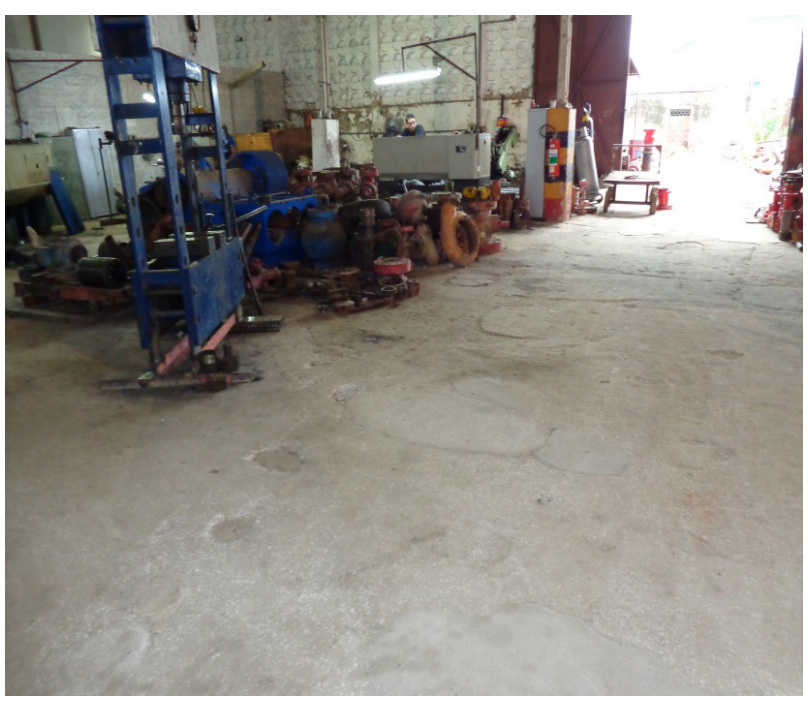

Figura 2-Áreas de circulação sem sinalização

Fonte: Autoria própria

(CTPS). Desse modo, é possível afirmar que os itens $12.135,12.137$ e 12.145 da NR-12.

Por fim, diante de outros possíveis requisitos específicos de segurança abordados na NR-12, os itens aplicáveis e também atendidos pela empresa em estudo são os 12.148 e 12.149, os quais abordam acerca das adequadas operações e intervenções de ferramentas, acessórios e materiais pelas máquinas e equipamentos.

Em relação as anomalias observadas, primeiramente, foi avaliada que as áreas de circulação não possuem as devidas demarcações, como solicita o item 12.6 e pode ser comprovado na Figura 2. Essa inconsistência encontrada na empresa prejudica na circulação das pessoas que se movimentam pelo ambiente de trabalho do empreendimento.

Em seguida, analisando as instalações elétricas e os equipamentos da empresa, percebe-se que a mesma não atende ao exposto na NR-10, como pede o item 12.14. Os quadros de energia das máquinas e equipamentos não possuem porta de acesso, não são mantidas permanentemente fechadas e nem apresentam um bom estado de conservação, limpos e livres de objetos e ferramentas, como apresentado no item 12.18 (a,c).

Os sistemas de segurança não paralisam os movimentos perigosos e demais riscos quando ocorrerem falhas ou situações anormais de trabalho, exceto quando é utilizado manualmente o dispositivo de parada de emergência, e com isso percebe-se uma não adequação ao item 12.39 da norma. Assim como não há dispositivo de parada de emergência monitorado por meio da de sistema de segurança, como cita o item 12.58 (f).

Quanto à sinalização instalada nas máqui- nas e equipamentos, observou-se que algumas dessas máquinas não apresentavam sinalização de segurança e outras, não tinham essa sinalização destacada ou claramente visível em seu corpo, com isso, prejudicando na alerta dos trabalhadores e terceiros sobre os riscos a que estão expostos e também se divergindo do que exige os itens 12.116, 12.116.3, 12.117 (a, b), 12.119.1 e 12.127 (c).

Ainda foi percebido que as cores amarela e azul, que deveriam ter sido adotadas para sinalizar a segurança das máquinas e equipamentos, não foram respeitadas, deste modo, também não obedecendo ao item $12.122(a, b)$.

Finalmente, outra não conformidade verificada na empresa em estudo foi os dos itens 12.153 e 12.153.1. Esses itens exigem a existência de um inventário atualizado das máquinas e equipamentos com suas devidas especificações e elaborados por um profissional qualificado e legalmente habilitado.

\subsection{Oportunidades de Melhorias}

Como observado as áreas de circulação não possuem as devidas demarcações, como solicita o item 12.6. Como sugestão para resolver esse problema, recomenda-se a correta sinalização com faixas amarelas e placas indicativas, como apresentado na Figura 3.

Para resolver o problema dos quadros de energia, sem porta de acesso ou qualquer tipo de proteção, sem identificação dos circuitos e sinalização quanto aos perigos de choque, recomenda-se a utilização de quadros adequados conforme a NR-10. Essa medida evita o de qualquer pessoa ao quadro, assim como contribui para a conservação do mesmo, já que este não ficará exposto á impurezas ou detritos.

Para a questão dos dispositivos de segu-

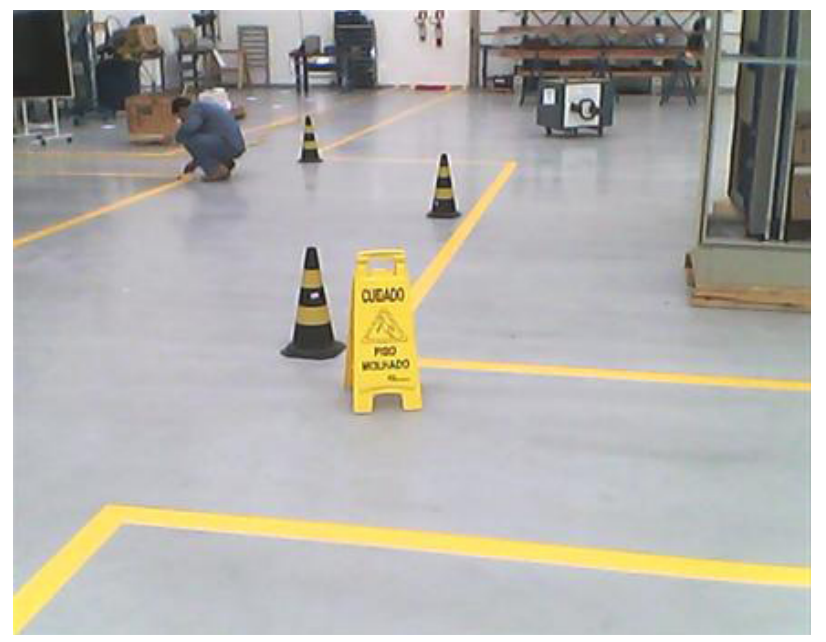

Figura 3-Áreas de circulação com sinalização adequada Fonte: LIMPETROL (2013) 
rança e emergência percebeu-se que a empresa não possui paradas automáticas de emergência, apenas manuais. Em caso de situações incomuns, esse não atendimento á norma pode causar sérios danos, desse modo, recomenda-se a utilização de um sistema de segurança que paralise movimentos perigosos e demais riscos quando ocorrerem falhas ou situações anormais de trabalho.

Com relação á manutenção, na empresa também não há nenhum livro, ficha ou qualquer sistema destinado ao registro de atividades relacionadas às atividades preventivas e corretivas das máquinas e equipamentos. Para isso, recomenda-se a implantação de um sistema, seja ele manual (fichas) ou automático (programas de computador), capaz de armazenar todas as informações á cerca das ações realizadas. Junto á essa medida recomenda-se também que seja utilizado um bloqueio mecânico ou elétrico, dependendo da finalidade do equipamento, para que o mesmo, durante o momento da inspeção, não possa causar acidentes provenientes do retorno das máquinas e equipamentos.

Quanto à sinalização instalada nas máquinas e equipamentos, observou-se que algumas dessas máquinas não apresentavam sinalização de segurança e outras, não tinham essa sinalização destacada ou claramente visível em seu corpo, com isso, prejudicando na alerta dos trabalhadores e terceiros sobre os riscos a que estão expostos.

Uma forma de solucionar esse problema vem a ser a utilização de placas, que alertam á todos que circulam por áreas próximas as máquinas o risco que as mesmas podem se submeter caso realizem manuseio inadequado ou não permitido.

Finalmente, outra não conformidade verificada na empresa em estudo foi a falta de atualização das informações referentes ás máquinas e equipamentos com todas as suas especificações. Para esse problema, é importante que haja a criação de um inventário atualizado com todas as informações relevantes e que os mesmos sejam elaborados por um profissional qualificado e legalmente habilitado.

\section{CONCLUSÃO}

Para que um bom profissional possa exercer sua função com competência, não existe nada melhor que a realização de práticas diárias sobre as atividades relacionadas á sua área. Para um Engenheiro de Segurança no Trabalho, atividades como a realização do check-list, para a verificação de adequações ou não ás normas, são fundamentais para o bom desenvolvimento desse profissional. E o uso de ferramentas que direcionem para observação de pontos fortes e fracos torna o processo mais dinâmico e mais robusto.

A aplicação do questionário foi válida, pois foi possível ver como o profissional habilitado e qualificado comporta-se diariamente, assim como, observar que medidas o mesmo adota para está sempre adequado as normas vigentes.

De uma forma geral a empresa atende a quase todos os requisitos da NR-12, principalmente no que diz respeito a questão do uso de EPI's e de segurança dos seus funcionários e métodos de trabalho. A mesma apresentou alguns problemas, também, como a questão das instalações elétricas em má conservação (isso aumenta o risco de haver incidentes com a eletricidade - choque, curto circuito, queima) e a falta de um registro ou documentação das atividades realizadas (isso é importante para a realização de uma vistoria e fiscalização mais eficiente). Para a resolução desses problemas, sugestões acessíveis e eficientes foram propostas, e que, se cumpridas, poderão melhorar ainda mais o rendimento e segurança de todos na empresa.

De uma forma geral, a metodologia desenvolvida foi considerada aceitável e apropriada para aplicações em indústrias com atividades semelhantes as analisadas neste trabalho.

\section{REFERÊNCIAS}

AGUIAR, L. A. Metodologias de Análise de Riscos - APP \& Hazop. Rio de Janeiro: 2011. Disponível em: <http://professor.ucg.br/SiteDocente/admin/ arquivosUpload/13179/material/APP_e_HAZOP. pdf $>$. Acesso em: 06 jul. 2012.

ALENCAR, L. Metodologias de análise de riscos: APP e HAZOP. Rio de Janeiro: UFRJ, 2009, 30f. Disponível em <http://www.saneamento.poli.ufrj. br $>$. Acesso em 21/06/2012.

\section{ALMEIDA, W. F. De. Trabalho Agrícola e sua Relação com Saúde/Doença. Rio de Janeiro, 1995.}

AMORIM, E. L. C. de. Ferramentas de Análise de Risco. Apostila do curso de Engenharia Ambiental da Universidade Federal de Alagoas, CTEC, Alagoas: 2010. Disponível em: < http://pt.scribd.com/ doc/71505557/Apostila-de-ferramentas-de-analise-de-risco>. Acesso em: 08 jul. 2012. 
AYRES, D. de O.; CORREAA, J. A. P. Manual de Prevenção de Acidentes do Trabalho. São Paulo, Editora ATLAS, 2001.

BOSSI et al. Como montar um QDC. Eletrodicas, Montes Claros. 2013. Disponível em: <http://www. eletrodicas.com.br/index.php?pg=7\&id_busca=9> . Acesso em : 18 abril 2013.

CAMACHO, E. N. Uma Proposta de Metodologia para Análise Quantitativa de Riscos Ambientais. (2004). Tese - Programa de Pós-graduação de Engenharia, Universidade Federal do Rio de Janeiro, 2004.

LIMPETROL Serviços e Pinturas. Galeria de imagens. Hotfrog, São Paulo. 2013. Disponível em: $<$ http://www.hotfrog.com.br/Empresas/Limpetrol-Servi\%C3\%A7os-e-Pinturas>. Acesso em: 18 abril 2013.

MINISTÉRIO DA SAÚDE DO BRASIL. Doenças relacionadas ao trabalho: manual de procedimentos para serviços de saúde. Ministério da Saúde do Brasil, Representação no Brasil da OPS/OMS. Brasília: Ministério da Saúde, 2001.

MINISTÉRIO DO TRABALHO E EMPREGO.

NR-12: Segurança no trabalho em máquinas e equipamentos. 2010. $75 \mathrm{p}$.

MINISTÉRIO DO TRABALHO E EMPREGO. Portaria $\mathrm{n}^{\circ} 3.214$, de 08 de junho de 1978. NR-6: Equipamento de proteção individual, Brasília, DF, 2012.

MINISTÉRIO DO TRABALHO E EMPREGO. Portaria $n^{\circ} 3.214$, de 08 de junho de 1978. NR-31: Segurança e saúde no trabalho na agricultura, pecuária silvicultura, exploração florestal e aqüicultura, Brasília, DF, 2012.

SALIBA, T. M. Curso Básico de Segurança e Higiene Ocupacional. 4. ed. São Paulo: LTR, 2011.

SEGURANÇA E SAÚDE NO TRABALHO. A "cor" como factor de saúde e segurança no traba1ho. 2012. Disponível em: <http://sst-ugt.blogspot. com.br/2012/02/cor-como-factor-de-saude-e-seguranca-no.html>. Acesso em : 18 abril 2013.

SESI-SEBRAE. Dicas de Prevenção de Acidentes e Doenças no Trabalho. SESI -SEBRAE, Saúde e Segurança no Trabalho : Micro e Pequenas Empre- sas / Luiz Augusto Damasceno Brasil (org.). - Brasília: SESI-DN, 2005.

SINALIZAÇÃO fácil. Placa cuidado risco de choque elétrico manuseio apenas por pessoas autorizadas. São Paulo. 2013. Disponível em: <http:// sinalizacaofacil.com.br/lojavirtual/productimage. php?product_id=540>. Acesso em: 18 abril 2013.

SOUZA, C. A. V. de; FREITAS, C. M. Acidentes de trabalho em refinaria de Petróleo. Revista de Saúde Pública, 2002; 36(5):576-83. 